\title{
Raising awareness of cognitive biases in clinical medicine: a pilot engagement study
}

\author{
Authors: Yang Chen ${ }^{A}$ and Myura Nagendran ${ }^{B}$
}

\section{Introduction}

Decision making in medicine is the final common pathway for all evidence-based treatments and interventions. There are over 30 recognised cognitive biases described in the literature. ${ }^{1}$ However, the phrases 'clinical decision making' and 'bias' appear only twice each in the 145-page postgraduate curriculum for general internal medicine. ${ }^{2}$ Given the paucity of explicit competency measures and teaching in the area, and the potentially low-hanging fruit offered by improvements in decision making, we sought to deliver a multifaceted intervention to increase the awareness and understanding of this subject among our profession.

\section{Methods}

We developed a 30-minute talk on cognitive biases after previously piloting the idea across 12 lectures at five NHS trusts. We used the feedback and experience gained to refine our content and presenting style. Our talk was pitched to be salient for the entire breadth of the medical profession and consisted of a rationale behind the importance of appreciating cognitive biases, a clinical case to illustrate such biases and specific debiasing strategies. The aim is for this grand round to be delivered at all 34 acute NHS trusts in London. ${ }^{3}$ We have deliberately split this task into phases, to ensure ongoing refinement of our intervention (Table 1).

Feedback was sought in real time at the end of the grand round and focused on two factors: the change in audience familiarity with cognitive biases and whether they would appreciate more teaching on this topic. All three questions were rated on a 5-point Likert scale, ranging 1 to 5 from very unfamiliar / strongly disagree to very familiar / strongly agree. Optional free-text qualitative comments were collected separately, along with the opt-in choice to join a clinician interest group, coordinated by email.

\section{Results and discussion}

At the time of writing, our talk has been presented at four grand rounds (North Middlesex, Newham, Whipps Cross, Whittington). Thirty-eight responses were received (range 6-15 per hospital). Post-talk familiarity (median 4, interquartile range (IQR) 4-5) was significantly higher than pre-talk familiarity (median 3, IQR 2-3),

\begin{tabular}{lll}
\hline \multicolumn{2}{l}{ Table 1. Intended sequence of grand round delivery } \\
\hline Phase & $\begin{array}{l}\text { Number of grand } \\
\text { rounds }\end{array}$ & Timeline \\
I & $8^{*}$ & February 2019 - May 2019 \\
II & $10^{+}$ & June 2019 - September 2019 \\
III & $16^{+}$ & October 2019 - March 2020
\end{tabular}

${ }^{*}$ Chosen due to previous clinical footprint of either author being leveraged ${ }^{\dagger}$ Pitched to grand round organising committees with evidence of ongoing positive feedback and support from consultant colleagues.

$p<0.001$. The proportion of the audience that agreed or strongly agreed that there should be more teaching on this topic was $95 \%$ ( 36 of 38 respondents). Sixty per cent of respondents, including trainees and consultants ( 23 of 38 respondents), have signed up to be part of the interest group.

\section{Conclusion}

Cognitive bias in clinical medicine is a topic that clinicians feel unfamiliar with. Familiarity is improved after a tried and tested teaching session, and the majority of respondents in this study are keen for further teaching on the topic.

\section{References}

1 Croskerry P. The importance of cognitive errors in diagnosis and strategies to minimize them. Acad Med 2003;78:775-80.

2 Joint Royal College of Physicians Training Board. Specialty training curriculum for general internal medicine 2009 (amendments made 2012). London: JRCPTB, 2012. www.jrcptb.org.uk/sites/default/ files/2009\% 20GIM \% 20\% 28amendment \% 202012\% 29.pdf [Accessed 20 March 2019].

3 NHS. London: CCGs and acute trusts. NHS, 2019. www.england.nhs. uk/london/ccg-trust/ [Accessed 20 March 2019].

Authors: ${ }^{\mathrm{A}}$ University College London, UK; ${ }^{\mathrm{B}}$ Imperial College London, UK 